\title{
Carvedilol-mediated antioxidant protection against doxorubicin-induced cardiac mitochondrial toxicity
}

\author{
Paulo J. Oliveira, ${ }^{\text {a }}$ James A. Bjork, ${ }^{\mathrm{b}}$ Maria S. Santos, ${ }^{\mathrm{a}}$ Richard L. Leino, ${ }^{\mathrm{c}}$ M. Kent Froberg, ${ }^{\mathrm{d}}$ \\ António J. Moreno, ${ }^{\mathrm{a}}$ and Kendall B. Wallace ${ }^{\mathrm{b}, *}$ \\ ${ }^{a}$ Centre of Neurosciences and Cellular Biology of Coimbra, Department of Zoology, University of Coimbra, Portugal \\ ${ }^{\mathrm{b}}$ Department of Biochemistry and Molecular Biology, School of Medicine, University of Minnesota, Duluth, MN 55812-2496, USA \\ ${ }^{c}$ Department of Anatomy and Cell Biology, School of Medicine, University of Minnesota, Duluth, MN 55812-2496, USA \\ ${ }^{\mathrm{d}}$ Department of Pathology, School of Medicine, University of Minnesota, Duluth, MN 55812-2496, USA
}

Received 21 November 2003; accepted 12 April 2004

Available online 20 July 2004

\begin{abstract}
The cardiotoxicity associated with doxorubicin (DOX) therapy limits the total cumulative dose and therapeutic success of active anticancer chemotherapy. Cardiac mitochondria are implicated as primary targets for DOX toxicity, which is believed to be mediated by the generation of highly reactive free radical species of oxygen from complex I of the mitochondrial electron transport chain. The objective of this study was to determine if the protection demonstrated by carvedilol (CV), a $\beta$-adrenergic receptor antagonist with strong antioxidant properties, against DOX-induced mitochondrial-mediated cardiomyopathy [Toxicol. Appl. Pharmacol. 185 (2002) 218] is attributable to its antioxidant properties or its $\beta$-adrenergic receptor antagonism. Our results confirm that DOX induces oxidative stress, mitochondrial dysfunction, and histopathological lesions in the cardiac tissue, all of which are inhibited by carvedilol. In contrast, atenolol (AT), a $\beta$ adrenergic receptor antagonist lacking antioxidant properties, preserved phosphate energy charge but failed to protect against any of the indexes of DOX-induced oxidative mitochondrial toxicity. We therefore conclude that the cardioprotective effects of carvedilol against DOXinduced mitochondrial cardiotoxicity are due to its inherent antioxidant activity and not to its $\beta$-adrenergic receptor antagonism.

(C) 2004 Elsevier Inc. All rights reserved.
\end{abstract}

Keywords: Mitochondria; Heart; Doxorubicin; Carvedilol; Atenolol; Permeability transition pore; Oxidative damage; Mitochondrionopathy

\section{Introduction}

The anthracycline quinone doxorubicin (DOX) has been widely prescribed in the treatment of several human tumors and leukemias. Despite its effectiveness, the clinical use of DOX is limited by a dose-dependent and cumulative cardiotoxicity (Hrdina et al., 2000). Many hypotheses have been advanced to explain the cardioselective toxicity of DOX (Olson and Mushlin, 1990). Because DOX undergoes redox cycling on mitochondrial Complex I to liberate highly reactive oxygen free radicals (Doroshow, 1983), oxidative

Abbreviations: DOX, doxorubicin; $\Delta \Psi$, mitochondrial transmembrane potential; $\mathrm{TPP}^{+}$, tetraphenylphosphonium cation; DMSO, dimethylsulfoxide; CV, carvedilol; AT, atenolol; SAL, saline; DTPA, 4,4-Dithiobis(phenylazide).

* Corresponding author. Department of Biochemistry and Molecular Biology, School of Medicine, University of Minnesota, 1035 University Drive, Room 255, Duluth, MN 55812-2496. Fax: +1-218-726-8014.

E-mail address: kwallace@d.umn.edu (K.B. Wallace). damage to the cardiac mitochondria and to the cardiomyocyte has been widely implicated as a primary cause for doxorubicin-induced cardiac toxicity (Lee et al., 1991; Xu et al., 2001). Several authors have shown diverse DOXinduced damage to mitochondrial membranes (Mimnaugh et al., 1985), proteins (Demant, 1991), and nucleic acids (Palmeira et al., 1997). One particular element is the triggering of the calcium-dependent mitochondrial permeability transition (MPT). This phenomenon, caused by enhanced oxidative stress and mitochondrial calcium overload (Bernardi, 1999; Kowaltowski and Vercesi, 1999), has been implicated to be responsible for mitochondrial and cellular dysfunction caused by DOX (Sokolove and Shinaberry, 1988; Solem et al., 1994, 1996; Zhou et al., 2001a, 2001b). Beyond cessation of mitochondrial ATP synthesis, another consequence associated with the MPT is the triggering of apoptotic cell death due to the release of proapoptotic factors from the dysfunctional mitochondria (Bernardi, 1999; Kowaltowski and Vercesi, 1999). 
Several authors have demonstrated that doxorubicin and its metabolites decrease mitochondrial calcium loading capacity both in vitro (Sokolove and Shinaberry, 1988) and in vivo (Solem et al., 1994, 1996; Zhou et al., 2001a, 2001b). The use of cyclosporin-A, a specific inhibitor of the MPT (Broekemeier et al., 1989), was critical in identifying the MPT as the principal cause for mitochondrial dysfunction caused by DOX exposure in vivo (Solem et al., 1994). Recent results demonstrate that cardiomyocytes isolated from DOX-treated animals are more susceptible to calcium-induced MPT and cell killing, both of which are prevented by cyclosporin-A (Solem et al., 1996; Zhou et al., 2001a). Evidence indicates that by inducing the MPT, DOX interferes with mitochondrial calcium regulation and that this is a principal feature in the pathogenesis associated with DOX-induced cardiomyopathy.

Because liberation of free radicals is central to the mechanism of DOX-induced damage to the myocardium, it is logical to consider antioxidants as primary candidates to counteract such toxic effects. In fact, several compounds with antioxidant properties have been investigated in vitro with some degree of success (DeAtley et al., 1999; Monti et al., 1996). However, the rate of success when performing in vivo studies has been less gratifying. In fact, molecules with antioxidant characteristics in vitro such as vitamin $\mathrm{E}$ and selenium (Van Vleet et al., 1980) or nimesulid (Kotsinas et al., 1999) were found to be of limited value in counteracting doxorubicin cardiotoxicity in vivo.

Carvedilol (CV, \{1-(carbazolyl-(4)-oxy)-3-(2-methoxyphenoxyethyl) amino)-propanol-(2)\}) is used clinically for the treatment of congestive heart failure, mild to moderate hypertension, and myocardial infarction. Carvedilol competitively blocks $\beta_{1}, \beta_{2}$, and $\alpha_{1}$-adrenergic receptors while displaying vasodilating properties. A distinctive characteristic of carvedilol is its potent antioxidant properties that are not shared by other $\beta$-adrenergic receptor antagonists (Yue et al., 1992). This antioxidant activity of carvedilol is attributed to its ability to chelate free iron (Noguchi et al., 2000), which is widely implicated in enhancing the free radical-mediated toxicity caused by doxorubicin. Carvedilol is superior to atenolol (AT), a $\beta$-adrenergic receptor antagonist without antioxidant properties, in diminishing DOXinduced negative impact on systolic blood pressure and left ventricular fractional shortening as well on increased lipid peroxidation (Matsui et al., 1999), which could either be explained by a direct effect on cardiac tissue or to vascular effects of the drug. More recently, the balance tilted for a predominant effect on the cardiac tissue as Santos et al. (2002) showed that carvedilol diminishes both the cardiac mitochondrial toxicity and histopathology caused by DOX. What has not yet been determined is whether this cardiospecific protection can be ascribed to the antioxidant or the general $\beta$-adrenergic receptor antagonism properties of carvedilol. The objective of the present work was to differentiate the relative contributions of the antioxidant and $\beta$-adrenergic receptor antagonism properties of carve- dilol in affording protection against the cardiac toxicity of DOX.

\section{Materials and methods}

Chemicals. Ultrapure sucrose was obtained from Schwarz/ Mann Biotech (Cleveland, OH). DOX was purchased from Pharmacia and Upjohn Co. (Kalamazoo, MI). CyclosporinA was a gift from Sandoz Pharmaceuticals (East Hanover, NJ) and carvedilol was obtained from Roche Pharmaceuticals (Lisbon, Portugal). All other chemicals were of the highest grade available from Sigma (St. Louis, MO). Both atenolol (AT) and carvedilol (CV) were dissolved in dimethylsulfoxide (DMSO). Doxorubicin (DOX) was dissolved in saline (SAL) solution.

Animals and treatment protocol. Male Sprague-Dawley rats (Harlan Labs, Madison, WI) weighing 200-300 g were maintained in AAALAC-accredited, climate-controlled facilities and allowed free access to food (Purina Chow) and water. All studies were carried out in accordance with the Guide for the Care and Use of Laboratory Animals. Rats were randomly divided among a total of six experimental groups (initial weights ranged from 173.5 to $186.5 \mathrm{~g}$ ): SAL + $\mathrm{DMSO}, \mathrm{SAL}+\mathrm{CV}, \mathrm{SAL}+\mathrm{AT}, \mathrm{DOX}+\mathrm{DMSO}, \mathrm{DOX}+\mathrm{CV}$, DOX + AT. DOX-injected rats received seven weekly sc injections of either DOX $\left(2 \mathrm{mg} \mathrm{kg}^{-1}\right)$ or an equivalent volume of SAL solution $\left(1 \mathrm{ml} \mathrm{kg}^{-1}\right)$. Where indicated, CV (1 $\mathrm{mg} \mathrm{kg}^{-1}$, ip), AT (1 $\mathrm{mg} \mathrm{kg}^{-1}$, ip), or an equivalent volume of DMSO $\left(1 \mathrm{ml} \mathrm{kg}^{-1}\right.$, ip) was co-administrated with DOX or saline solution. DOX dosage was established from previous studies that showed cardiac mitochondrial damage and histopathology (Solem et al., 1994; Zhou et al., 2001b). The CV regimen was according to the work of Santos et al. (2002), where convincing protection against DOX cardioselective toxicity was afforded by carvedilol administration. Clinical trials demonstrated that both compounds, at the same dosages, were equally effective at reducing blood pressure in patients (Hall et al., 1991; McTavish et al., 1993), so an equivalent dosage of both compounds was administrated. The animals were killed by decapitation 1 week after the last injection and the hearts immediately excised to cold buffer for mitochondrial isolation. Body and heart weights were recorded on the day of the experiments.

Isolation of cardiac mitochondria. Cardiac mitochondria were prepared by differential centrifugation (Oliveira et al., 2000). Briefly, the hearts were finely minced in an ice-cold isolation medium containing $250 \mathrm{mM}$ sucrose, $1 \mathrm{mM}$ EGTA, $10 \mathrm{mM}$ HEPES-KOH (pH 7.4), and $0.1 \%$ defatted BSA. The minced tissue was suspended in $40 \mathrm{ml}$ of isolation medium containing $0.5 \mathrm{mg}$ protease Type VIII (Sigma P5390) per $g$ of tissue and homogenized with a tightly fitted homogenizer (Teflon: glass pestle). The suspension was incubated for $1 \mathrm{~min}\left(4{ }^{\circ} \mathrm{C}\right)$ and then re-homogenized. The 
homogenate was then centrifuged at $9500 \times g$ for $10 \mathrm{~min}$. The supernatant was decanted and the pellet was gently homogenized to its original volume with a loose-fitting homogenizer. The suspension was centrifuged at $900 \times g$ for 10 min and the resulting supernatant was centrifuged at $9000 \times g$ for $10 \mathrm{~min}$. This pellet was resuspended using a brush and re-pelleted twice at $9000 \times g$ for $10 \mathrm{~min}$. EGTA and defatted BSA were omitted from the final washing medium. Mitochondrial protein content was determined by the Bradford method calibrated with BSA (Bradford, 1976).

TPP ${ }^{+}$uptake. The mitochondrial accumulation of tetraphenylphosphonium $\left(\mathrm{TPP}^{+}\right)$(indirect measurement of mitochondrial electrical potential, $\Delta \Psi)$ was performed using a $\mathrm{TPP}^{+}$-selective electrode and a $\mathrm{AgCl}$ reference electrode (Kamo et al., 1979). Mitochondrial protein $(0.5 \mathrm{mg})$ was suspended in $2 \mathrm{ml}$ of reaction buffer ( $200 \mathrm{mM}$ sucrose, 10 $\mathrm{mM}$ TRIS-MOPS, $10 \mu \mathrm{M}$ EGTA, and $5 \mathrm{mM} \mathrm{KH}_{2} \mathrm{PO}_{4}, \mathrm{pH}$ $7.4,25{ }^{\circ} \mathrm{C}$ ) supplemented with $2 \mu \mathrm{M}$ rotenone and $0.5 \mu \mathrm{M}$ $\mathrm{TPP}^{+}$. Sequential additions of $0.5 \mu \mathrm{M} \mathrm{TPP}{ }^{+}$were made to calibrate the system and calculate the amount of $\mathrm{TPP}^{+}$taken by mitochondria. Absolute values for membrane potential (in millivolts) were determined from the equation originally proposed by Kamo et al. (1979). Succinate was added to the mitochondrial suspension containing a total of $3 \mu \mathrm{M} \mathrm{TPP}$ in the absence and presence of $20 \mu \mathrm{M}$ of calcium.

Oxygen consumption. Oxygen consumption by isolated heart mitochondria was monitored polarographically with a Clark oxygen electrode connected to a suitable recorder. Reactions were carried out at $25{ }^{\circ} \mathrm{C}$ in $1 \mathrm{ml}$ of the media containing $200 \mathrm{mM}$ sucrose, $10 \mathrm{mM}$ TRIS-MOPS, $10 \mu \mathrm{M}$

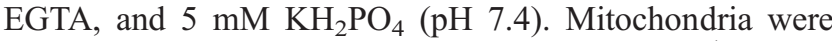
suspended at a concentration of $0.5 \mathrm{mg} \mathrm{m}^{-1}$ in the respiratory medium. State 4 respiration was measured in the presence of $5 \mathrm{mM}$ glutamate/malate. ADP (100 nmol) was added to induce state 3 respiration. The respiratory control ratio (RCR) was calculated as the ratio between state 3 and state 4 respiration and the ADP/O was calculated according to standard procedures (Estabrook, 1967).

Mitochondrial swelling. Mitochondrial volume changes were followed by the decrease of optical density measured at $540 \mathrm{~nm}$ with a Beckman DU 7400 spectrophotometer equipped with a magnetic stirrer assembly. The assays were performed in $2 \mathrm{ml}$ of $200 \mathrm{mM}$ sucrose, $10 \mathrm{mM}$ TRISMOPS, $10 \mu \mathrm{M}$ EGTA, $5 \mathrm{mM} \mathrm{KH} \mathrm{PO}_{4}\left(\mathrm{pH} \mathrm{7.4,25}{ }^{\circ} \mathrm{C}\right.$ ), and $2 \mu \mathrm{M}$ rotenone to which was added $0.5 \mathrm{mg}$ of mitochondrial protein. Succinate was added after calcium addition. Swelling amplitude was calculated as the difference between initial (pre-succinate addition) and final optical density.

Calcium loading capacity. Extramitochondrial free $\mathrm{Ca}^{2+}$ was measured with the hexapotassium salt of the fluorescence probe Calcium Green 5-N (Rajdev and Reynolds, 1993). Heart mitochondria (15 ng) were suspended in 300 $\mu \mathrm{l}$ of buffer containing $200 \mathrm{mM}$ sucrose, $10 \mathrm{mM}$ TRIS-


Calcium Green 5-N, $1 \mu \mathrm{M}$ rotenone, and 2.1 pmol calcium. Calcium Green 5-N fluorescence was continuously recorded in a Lab-systems type 374 plate reader with excitation and emission wavelengths of 485 and $538 \mathrm{~nm}$, respectively. Calcium loading was initiated by the addition of $1 \mathrm{mM}$ succinate. To calculate the MPT-dependent decrease in calcium loading capacity, the same measurements were repeated in the presence of cyclosporin-A to inhibit the MPT (Zhou et al., 2001b). Mitochondrial calcium loading capacity was expressed as the ratio of the maximum fluorescence change in the absence and presence of cyclosporin-A. At the end of each assay, EGTA was added in excess to complex all free calcium and calibrate the base line.

Tissue adenine nucleotide quantification. Tissue adenine nucleotide extraction was performed with an acidic extraction procedure with $0.625 \mathrm{~N} \mathrm{HClO}_{4}$ and neutralized with 5 $\mathrm{N}$ KOH (Jones, 1981). The resulting supernatant was filtered through a Millipore $0.45 \mu \mathrm{m}$ filter and the $\mathrm{pH}$ was set to 7 . The nucleotides were separated by reverse-phase high performance liquid chromatography consisting of a Beckman 126 Binary Pump Model and a 166 Variable UV detector controlled by a computer. The detection wavelength was $254 \mathrm{~nm}$, and the column was a Lichrospher 100RP-18 $(5 \mu \mathrm{m})$ from Merck (Darmstadt, Germany). An isocratic elution with $100 \mathrm{mM}$ phosphate buffer $\left(\mathrm{KH}_{2} \mathrm{PO}_{4}\right), \mathrm{pH} 6.5$ and $1 \%$ methanol was performed with a flow rate of $1 \mathrm{ml}$ $\min ^{-1}$. The time required for each analysis was $5 \mathrm{~min}$.

Quantification of protein-bound carbonyls. Protein-reactive carbonyls in tissue samples were analyzed according to Levine et al. (1990) with slight modifications. A sample of tissue $(100-300 \mathrm{mg})$ was homogenized in three volumes of buffer composed of $10 \mathrm{mM}$ HEPES, $137 \mathrm{mM} \mathrm{NaCl}$, 4.6 $\mathrm{mM} \mathrm{KCl}, 2 \mathrm{mM} \mathrm{KH} \mathrm{PO}_{4}, 0.6 \mathrm{mM} \mathrm{MgSO}$, and $1.1 \mathrm{mM}$ EDTA (pH 7.4). The insoluble material was discarded. Two 50- $\mu$ l aliquots from each sample were taken and the protein precipitated with $0.5 \mathrm{ml}$ ice-cold trichloroacetic acid $(10 \%$ $\mathrm{w} / \mathrm{v})$. After a 10 -min incubation at $4{ }^{\circ} \mathrm{C}$, samples were centrifuged at $11000 \times g$ for $3 \mathrm{~min}$. One of the protein pellets was resuspended in $0.5 \mathrm{ml}$ of $0.2 \%(\mathrm{w} / \mathrm{v}) 2,4-$ dinitrophenylhydrazine (DNPH)/2 M HCl. The other protein sample was resuspended in $0.5 \mathrm{ml}$ of $2 \mathrm{M} \mathrm{HCl}$ (and used as blank). The pellets were gently resuspended and continuously mixed at room temperature for $1 \mathrm{~h}$. The samples were then precipitated with $0.5 \mathrm{ml}$ of $10 \%$ TCA and centrifuged at $11000 \mathrm{~g}$ for $3 \mathrm{~min}$. The pellets were gently washed with $1 \mathrm{ml}$ of ethanol-ethyl acetate $(1: 1 ; \mathrm{v} / \mathrm{v})$ to remove unreacted DNPH reagent and allowed to stand for $10 \mathrm{~min}$. The samples were centrifuged for $5 \mathrm{~min}$ at $11000 \times g$ and the supernatant discarded. The washing procedure was repeated twice. The resulting protein pellet was gently resuspended in $1.0 \mathrm{ml}$ of $6 \mathrm{M}$ guanidine with 20 
$\mathrm{mM}$ sodium phosphate buffer ( $\mathrm{pH}$ 6.5). The samples were left for $10 \mathrm{~min}$ at room temperature before reading the absorbance at $360 \mathrm{~nm}$ (DPNH-protein carbonyl adduct) and $280 \mathrm{~nm}$ (protein concentration). Protein carbonyl concentration was estimated from the ratio A360/A280 after subtracting the blanks.

Superoxide dismutase (SOD) activity. Total SOD activity in homogenized heart tissue was determined according to Prohaska (1983) by monitoring the rate of autoxidation of pyrogallol at $320 \mathrm{~nm}$. The homogenization buffer consisted of $50 \mathrm{mM} \mathrm{KPO}_{4}, \mathrm{pH} 7.4$. The reaction buffer $\left(37^{\circ} \mathrm{C}\right)$ was $50 \mathrm{mM}$ TAPS ((2-Hydroxy-1,1-bis(hydroxymethyl)ethyl)amino)-1-propanesulfonic acid $N$-(Tris(hydroxymethyl)methyl)-3-aminopropanesulfonic acid), $0.1 \mathrm{mM} \mathrm{4,4-}$ Dithio-bis(phenylazide) (DTPA), $\mathrm{pH}$ 8.2. Pyrogallol (4 $\mu$ l of a $10 \mathrm{mM}$ stock solution in a final volume of $1 \mathrm{ml}$ ) was added to the cuvette to start the reaction and the rate of absorbance increase was measured for $1 \mathrm{~min}$. One Unit of SOD activity was defined as the amount of sample required to inhibit the autoxidation of pyrogallol by $50 \%$, and the activity is expressed as Units per $\mathrm{mg}$ of protein (Prohaska, 1983).

Glutathione peroxidase (GPx) activity. Tissue GPx activity was determined spectrophotometrically by the decrease in NADPH absorbance at $340 \mathrm{~nm}$. Measurements were performed in $1 \mathrm{ml}$ of reaction buffer containing $100 \mathrm{mM}$ HEPES and 0.1 mM DTPA, $\mathrm{pH} 7.4$, supplemented with 1 $\mathrm{mM}$ GSH, NADPH, and $50 \mu \mathrm{l}$ of commercial glutathione reductase (Gred) $0.3 \mathrm{U} \mathrm{ml}^{-1}$. After sample addition (1:100 dilution from a homogenate), the reaction was started by adding $250 \mu \mathrm{M}$ tBHP. The difference between the rates before and after tBHP addition was calculated and expressed as nmol NADPH consumed per min per mg protein $\left(\varepsilon_{\mathrm{NADPH}}=6.22 \mathrm{mM}^{-1} \mathrm{~cm}^{-1}\right)$.

Glutathione reductase (Gred) activity. Gred activity was determined according to the method of Yin et al. (1998). Samples were prepared as described for SOD measurements. The assay buffer consisted of $0.2 \mathrm{M} \mathrm{KH}_{2} \mathrm{PO}_{4}$ supplemented with $2 \mathrm{mM}$ EDTA, and the reaction started by adding NADPH in excess and, 1 min later, $1 \mu \mathrm{M}$ GSSG. The difference between the rates before and after GSSG addition was calculated and expressed as nmol $\mathrm{NADPH}$ consumed per min per $\mathrm{mg}$ protein $\left(\varepsilon_{\mathrm{NADPH}}=\right.$ $\left.6.22 \mathrm{mM}^{-1} \mathrm{~cm}^{-1}\right)$.
Electron microscopy of cardiac tissue. Representative electron micrographs from myocytes were obtained as previously described (Santos et al., 2002; Zhou et al., 2001b). Briefly, small blocks of cardiac muscle from the midportion of the lateral wall of the left ventricle were fixed in $2.5 \%$ glutaraldehyde- $2 \%$ formaldehyde in $0.1 \mathrm{M}$ phosphate buffer ( $\mathrm{pH} 7.4)$, postfixed in $1 \%$ osmium tetroxide in the same buffer, dehydrated in graded acetone solutions, and finally embedded in epon-araldite. Thin sections were stained with lead citrate and uranyl acetate. Sections were scored from both the extent (number of damaged cardiac myocytes) and the severity of the cellular changes according to the same criteria as prior studies (Santos et al., 2002; Zhou et al., 2001b). The extent of damage is reported as the absolute number of affected cells within a $202500 \mu \mathrm{m}^{2}$ total cross-sectional region of ventricular wall. Severity was scored on a scale of 0-3 (Santos et al., 2002; Zhou et al., 2001b). All slides were scored independently by an examiner who was blinded to the identity of each sample.

Statistical analysis. The results are presented as the mean \pm SEM of at least six independent experiments. One-way analysis of variance (ANOVA) of log-transformed data followed by Newman-Keuls post-test was used as statistical treatment. A $P$ value $<0.05$ was considered statistically significant.

\section{Results}

Long-term treatment with DOX caused several alterations, including decreased final body weight gain and reduced heart size (Table 1). The decrease in heart weight was proportional to body weight reduction, resulting in an unchanged ratio between heart and body weight (Table 1). Although both carvedilol and atenolol prevented the decreased heart weight associated with DOX treatment, neither drug prevented DOX effects on body weight. Neither carvedilol alone nor atenolol alone (in the absence of DOX) affected the heart or body weight.

No differences in the respiratory rates in glutamate/ malate-energized mitochondria were found between any of the treatment groups (Table 2). State 4 respiratory activities varied between 40 and 60 natm $\mathrm{O} \mathrm{min}^{-1} \mathrm{mg}^{-1}$ protein. RCR values were between $6.4 \pm 1.0$ in the SAL $+\mathrm{CV}$ group and $8.0 \pm 1.4$ in the SAL + DMSO group (Table 2). The index for mitochondrial phosphorylation efficiency (the

Table 1

Comparison of body and heart weight among experimental groups

\begin{tabular}{|c|c|c|c|c|c|c|}
\hline & Saline + DMSO & Saline + Carvedilol & Saline + Atenolol & $\mathrm{DOX}+\mathrm{DMSO}$ & DOX + Carvedilol & DOX + Atenolol \\
\hline Heart weight (g) & $1.47 \pm 0.04$ & $1.49 \pm 0.06$ & $1.48 \pm 0.05$ & $1.23 \pm 0.04 *$ & $1.32 \pm 0.08$ & $1.25 \pm 0.06$ \\
\hline Final body weight $(\mathrm{g})$ & $379.0 \pm 9.66$ & $378.0 \pm 11.10$ & $372.25 \pm 6.98$ & $298.38 \pm 10.72^{*}$ & $290.61 \pm 6.39 *$ & $312.31 \pm 9.86^{*}$ \\
\hline $\mathrm{HW} / \mathrm{BW}(\times 1000)$ & $3.89 \pm 0.05$ & $3.94 \pm 0.15$ & $3.99 \pm 0.14$ & $4.14 \pm 0.18$ & $4.55 \pm 0.28$ & $4.01 \pm 0.18$ \\
\hline
\end{tabular}

The values are the means \pm SEM of eight animals in each experimental group.

$* P<0.05$ vs. the corresponding saline treatment. 
Table 2

Respiratory parameters in glutamate/malate-energized mitochondria for all experimental groups

\begin{tabular}{|c|c|c|c|c|c|c|}
\hline & Saline + DMSO & Saline + Carvedilol & Saline + Atenolol & DOX + DMSO & DOX + Carvedilol & DOX + Atenolol \\
\hline $\begin{array}{l}\text { State } 4 \\
\qquad \text { (natm } \mathrm{O} \min ^{-1} \mathrm{mg}^{-1} \text { protein) }\end{array}$ & $47.9 \pm 5.6$ & $57.8 \pm 7.2$ & $45.7 \pm 7.7$ & $40.2 \pm 1.2$ & $45.5 \pm 4.1$ & $42.6 \pm 3.1$ \\
\hline $\begin{array}{l}\text { State } 3 \\
\qquad \text { (natm } \mathrm{O} \mathrm{min} \mathrm{mg}^{-1} \mathrm{mg}^{-1} \text { protein) }\end{array}$ & $360.6 \pm 37.8$ & $357.9 \pm 51.4$ & $333.1 \pm 62.1$ & $336.8 \pm 37.6$ & $327.1 \pm 47.8$ & $270.2 \pm 5.6$ \\
\hline RCR & $8.0 \pm 1.4$ & $6.4 \pm 1.0$ & $7.3 \pm 0.6$ & $7.7 \pm 0.7$ & $7.7 \pm 0.6$ & $6.4 \pm 0.3$ \\
\hline $\mathrm{ADP} / \mathrm{O}$ & $2.6 \pm 0.2$ & $2.7 \pm 0.3$ & $2.6 \pm 0.1$ & $2.8 \pm 0.2$ & $2.7 \pm 0.2$ & $2.8 \pm 0.2$ \\
\hline
\end{tabular}

The values are the means \pm SEM of 4-5 animals in each group. There were no significant differences among any experimental group.

$\mathrm{ADP} / \mathrm{O}$ ratio) also was unchanged among all six treatment groups.

In the absence of calcium, succinate-energized mitochondria from all six experimental groups were able to accumulate the same amount of $\mathrm{TPP}^{+}$(around 9.3 to 9.7 nmol mg ${ }^{-1}$ protein, data not shown), indicating comparable $\Delta \Psi$ in all experimental groups. $\mathrm{TPP}^{+}$uptake was reduced by adding $20 \mu \mathrm{M}$ of calcium; however, there were still no significant differences in $\Delta \Psi$ among the various treatment groups (Fig. 1). Although $\Delta \Psi$ was lower in the DOX + DMSO group, the difference was not statistically different from SAL + DMSO, possibly due to the large variability in $\mathrm{TPP}^{+}$measurements. Likewise, neither $\mathrm{CV}$ nor AT, either alone or in conjunction with DOX, altered cardiac mitochondrial $\Delta \Psi$.

Mitochondrial swelling is indicative of susceptibility to calcium-induced MPT. As illustrated in Fig. 2, cardiac mitochondria from the DOX + DMSO group were more susceptible to calcium-induced mitochondrial swelling than were controls. Co-administration of carvedilol, but not atenolol, prevented the increased calcium-induced swelling caused by DOX treatment. Neither CV nor AT alone altered the susceptibility to the MPT, and there was no statistical

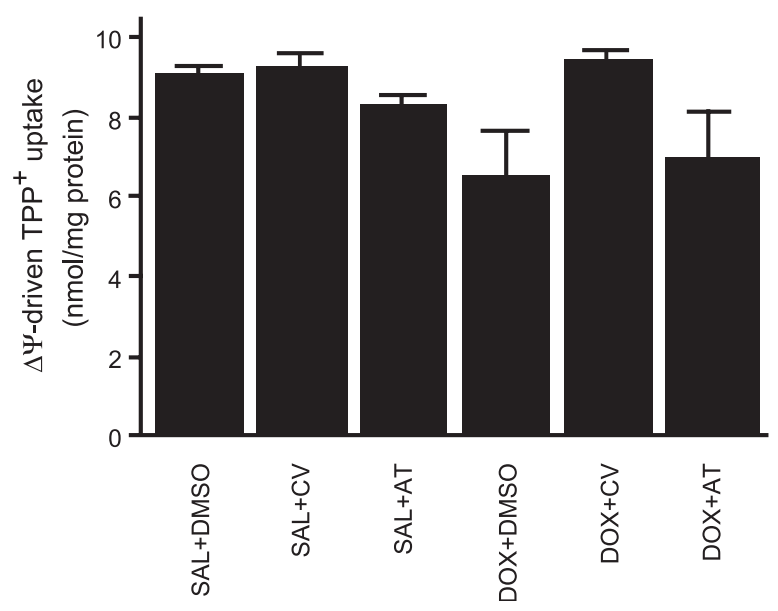

Fig. 1. Quantification of $\Delta \Psi$-dependent $\mathrm{TPP}^{+}$accumulation by succinateenergized cardiac mitochondria in the presence of $20 \mu \mathrm{M}$ calcium. For the SAL + DMSO group, $\Delta \Psi$ values were $-156.8 \pm 8.2 \mathrm{mV}$ in the presence of $20 \mu \mathrm{M}$ calcium and $188.1 \pm 15.6 \mathrm{mV}$ in its absence. The values shown represent the means \pm SEM of 4-5 animals in each group. There were no statistically significant differences among any of the treatment groups $(P>0.05)$. difference in swelling amplitude between the DOX $+\mathrm{CV}$ and DOX + AT treatment groups.

We have previously shown that mitochondrial calcium loading capacity is one of the most sensitive and reliable indicators of drug-induced mitochondrial dysfunction (Zhou et al., 2001b). Measurement of mitochondrial calcium loading capacity in succinate-energized mitochondria was performed using the fluorescent probe Calcium Green 5-N. Mitochondrial calcium loading capacity was similar in all three saline groups (Fig. 3), indicating that atenolol or carvedilol alone did not influence mitochondrial calcium loading capacity. In contrast, DOX administration caused a significant decrease in calcium loading capacity, which was restored by co-administrating carvedilol, but not by atenolol. Mitochondrial calcium loading was significantly lower in the DOX + DMSO-treated animals compared to all other treatment groups, except for DOX + AT. The in vitro inhibition by cyclosporin-A of DOX-induced decrease in calcium loading capacity [15] is evidence that this difference is attributable to induction of the MPT by DOX.

A classic and stable indicator for oxidative damage is the accumulation of protein-bound carbonyl groups in affected tissues (Rajdev and Reynolds, 1993). Fig. 4 illustrates the content of protein-bound carbonyl groups in the cardiac tissue from the various treatment groups. There was a large

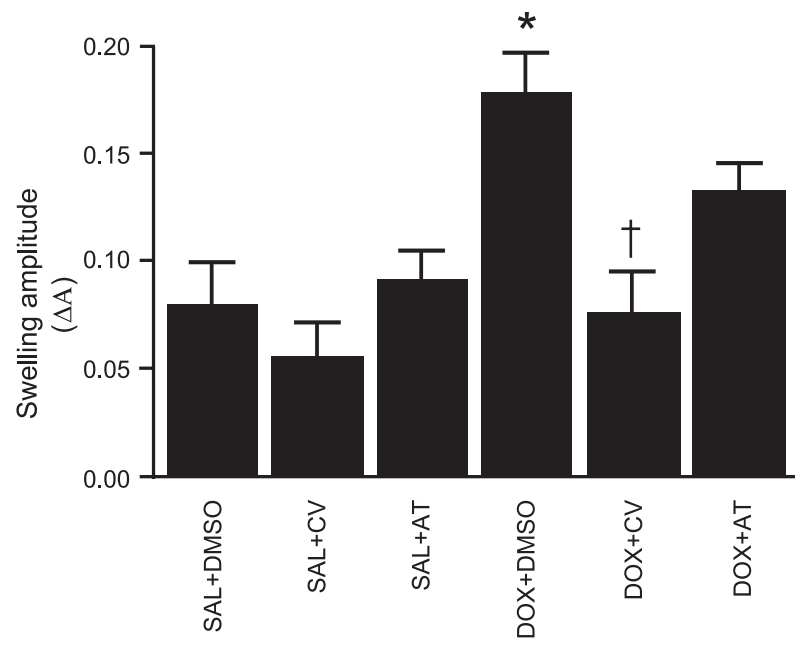

Fig. 2. Mitochondrial swelling. Calcium $(20 \mu \mathrm{M})$ was added before succinate energization. The values represent the means \pm SEM of 4-5 animals in each group. $* P<0.05$ vs. SAL + DMSO, $\uparrow P<0.05$ vs. DOX + DMSO. 


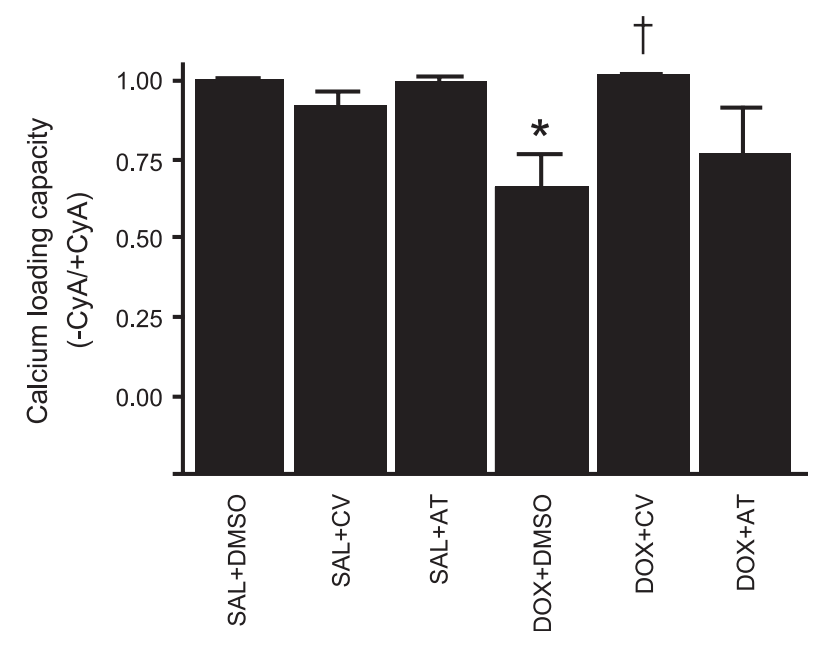

Fig. 3. Calcium loading capacity in succinate-energized mitochondria under the conditions of Fig. 1. The results are presented as the ratio between the minimum fluorescence obtained in the presence and absence of cyclosporin-A. The values are the means \pm SEM of $4-5$ animals in each group. $* P<0.05$ vs. SAL + DMSO, $\dagger P<0.05$ vs. DOX + DMSO.

increase ( $>5$-fold) in the concentration of carbonyl groups in cardiac tissue of animals injected with DOX + DMSO, an effect that was prevented by co-administrating carvedilol $(\mathrm{DOX}+\mathrm{CV})$, but not by atenolol $(\mathrm{DOX}+\mathrm{AT})$. Neither carvedilol nor atenolol alone altered the amount of protein carbonyls in heart tissue from saline-injected rats.

DOX induced-changes in antioxidant enzymes were determined in frozen cardiac tissue. Cardiac superoxide dismutase (SOD), glutathione peroxidase (GPx), and glutathione reductase (Gred) activities were not altered by any of the treatments (Fig. 5). There was a tendency for antioxidant enzyme activity to be slightly higher in the heart tissue from DOX-treated rats, but these differences were not statistically significant among any of the experimental treatment groups.



Fig. 4. Protein carbonyl groups quantified by the DPNH-sensitive assay. Values are presented as the ratio A360/A280 for each DNPH-sample, after subtraction of A360/A280 for each DNPH-free sample. Values are the mean \pm SEM of $4-5$ animals in each experimental group. $* P<0.05$ vs. corresponding saline treatment, $\dagger P<0.05$ vs. DOX + DMSO.
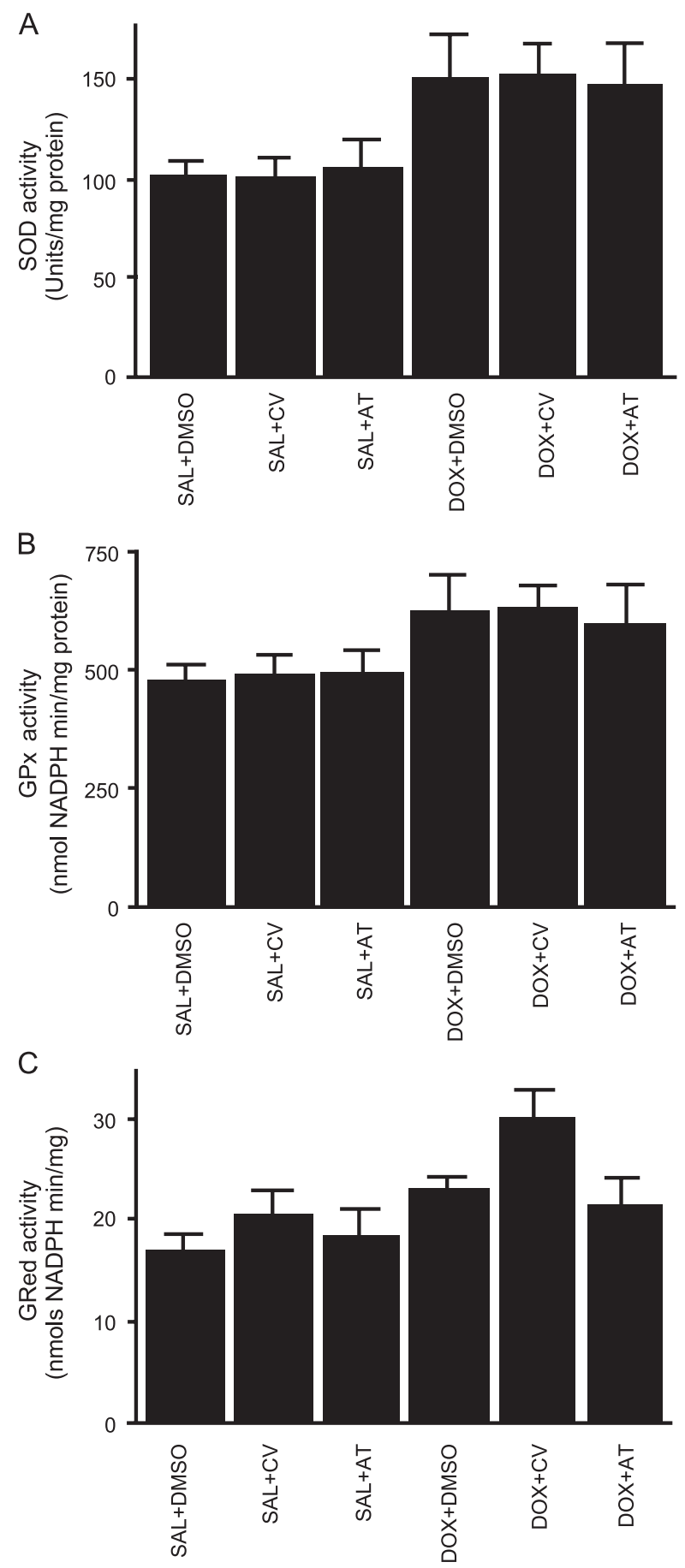

Fig. 5. Antioxidant enzyme activities determined as described in Materials and methods. (A) Superoxide dismutase, (B) glutathione peroxidase, (C) glutathione reductase. Values represent the means \pm SEM of 4-5 different samples. There were no statistically significant differences among any of the treatment groups $(P>0.05)$.

ATP and ADP concentrations in the cardiac tissue were unchanged in all the six treatment groups (Table 3 ). However, the ratio of ATP to ADP concentration was statistically lower in hearts from DOX + DMSO rats when compared to the SAL + DMSO group. Most importantly, both carvedilol and atenolol prevented the reduction in the tissue ATP/ADP 
Table 3

Cardiac tissue ATP and ADP

\begin{tabular}{lcccccc}
\hline & Saline + DMSO & Saline + Carvedilol & Saline + Atenolol & DOX + DMSO & DOX + Carvedilol & DOX + Atenolol \\
\hline ATP $\left(\mathrm{pmol} \mathrm{mg}^{-1}\right.$ tissue) & $284.0 \pm 31.1$ & $309.8 \pm 49.4$ & $291.3 \pm 53.2$ & $163.1 \pm 37.7$ & $232.0 \pm 20.3$ & $269.6 \pm 57.2$ \\
ADP $\left(\mathrm{pmol} \mathrm{mg}{ }^{-1}\right.$ tissue) & $546.9 \pm 92.0$ & $580.9 \pm 68.1$ & $462.6 \pm 103.5$ & $457.4 \pm 50.3$ & $418.1 \pm 54.9$ & $441.4 \pm 74.3$ \\
ATP/ADP & $0.53 \pm 0.04$ & $0.52 \pm 0.05$ & $0.67 \pm 0.07$ & $0.34 \pm 0.05^{*}$ & $0.56 \pm 0.03^{\dagger}$ & $0.60 \pm 0.07^{\dagger}$ \\
\hline
\end{tabular}

The values are means \pm SEM of 4-5 animals in each experimental group.

$* P<0.05$ vs. correspondent saline treatment.

${ }^{\dagger} P<0.05$ vs. DOX + DMSO.

ratio caused by DOX administration, and there was no statistical difference in the ATP/ADP ratio between DOX + $\mathrm{CV}$ and $\mathrm{DOX}+\mathrm{AT}$ treatment groups.

When examined by electron microscopy, cardiac myocytes from the SAL + DMSO group showed a normal appearance (Fig. 6A). Not surprisingly, ultrastructural changes to the myocardium were observed in the DOX + DMSO group (Fig. 6B). Pathological changes included cytoplasmic vacuolation involving distention of the Ttubules and sarcoplasmic reticulum, myofibrillar disorgani- zation and loss, mitochondrial swelling and loss, and cellular edema. While atenolol was not able to prevent DOX-induced myocyte damage (Fig. 6D), carvedilol prevented most of the cardiac histopathology caused by DOX (Fig. 6C): distention of the T-tubules and sarcoplasmic reticulum, when present, was much less pronounced and mitochondrial and myofibrillar damage were not observed. A semiquantitative analysis of these histopathological changes revealed that substantial interindividual variability in susceptibility to DOX 2 of the five DOX-DMSO-treated


Fig. 6. Representative electron micrograph of cardiac tissue from control and treated animals (magnification: $11000 \times$ ). $($ A) $\mathrm{SAL}+\mathrm{DMSO}$ group, $(\mathrm{B}) \mathrm{DOX}+$ DMSO group, (C) DOX + CV, (D) DOX + AT. Notice the cytoplasmic vacuolation, mitochondrial loss and disorganization, and the cellular fluid accumulation in the DOX + DMSO and DOX + AT groups. 
Table 4

Cardiac histopathology for rats treated with doxorubicin and either carvedilol or atenolol

\begin{tabular}{llll}
\hline & Saline + DMSO & DOX + DMSO & DOX + Atenolol \\
\hline Extent of cell damage $^{\mathrm{a}}$ & $0.00 \pm 0.00$ & $9.20 \pm 7.98$ & $2.60 \pm 1.52$ \\
Severity of cell damage $^{\mathrm{b}}$ & $0.00 \pm 0.00$ & $2.40 \pm 0.55$ & $1.40 \pm 0.55^{*}$ \\
\hline
\end{tabular}

${ }^{a}$ Extent of cell damage represents the mean $( \pm S D)$ number of damaged myocytes in a $202500 \mu \mathrm{m}^{2}$ area.

${ }^{\mathrm{b}}$ Severity of cell damage is expressed on a blinded scale of $0-3$.

$* P<0.05$, significantly different from doxorubicin treatment (DOX + DMSO) $(n=5)$.

rats expressed little, if any, histopathology (Table 4). Accordingly, when analyzed from the extent of cardiac injury, the experimental variability in the DOX-DMSO treatment group precluded statistical significance for cardioprotection by either carvedilol or atenolol. However, when analyzed by the severity of cardiac injury, carvedilol afforded statistically significant cardioprotection against DOX-induced cardiac histopathology, whereas atenolol did not (Table 4).

\section{Discussion}

It is very well established that DOX, by stimulating free radical generation on the electron transport chain, induces mitochondrial dysfunction, particularly in the myocardium (Santos et al., 2002; Sokolove and Shinaberry, 1988; Solem et al., 1994, 1996; Zhou et al., 2001a, 2001b). The present investigation confirms this mitochondrionopathy as reflected by the substantially decreased calcium loading capacity and increased sensitivity to calcium-induced swelling of cardiac mitochondria isolated from DOX-injected rats (Figs. 1-3), which is the same as that reported previously from this laboratory (Santos et al., 2002; Solem et al., 1994). However, unlike previous investigations, cardiac mitochondria from DOX-treated rats did not exhibit a depression of respiratory activities, despite receiving the same treatment regimen. In reflecting on the source of this difference, a few possibilities were identified. It may be because in this particular investigation, the mitochondrial pellets were more extensively washed than in previous studies, yielding a more homogenous preparation containing fewer light mitochondria than in prior investigations. Alternatively, it may be because the current investigation included the calciumchelator EGTA $(10 \mu \mathrm{M})$ in the reaction buffer. We have previously shown that the effects of DOX on mitochondrial respiration are mediated through a calcium-dependent induction of the mitochondrial permeability transition, which is suppressed in the presence of EGTA. Regardless, we interpret the present results as supporting the contention that measurement of respiration is not a sensitive and definitive indicator of mitochondrial dysfunction. Instead, it is the decrease in calcium-loading capacity and loss of mitochondrial calcium homeostasis that is an early, more sensitive, and consistent indication of mitochondrial dysfunction caused by drug treatment (Zhou et al., 2001b).

DOX-induced mitochondrial cardiomyopathy is characterized by the accumulation of oxidized lipids, proteins, and
DNA, mitochondrial dysfunction leading to a systolic failure, and extensive cardiac tissue histopathology characterized by disorganization of the sarcomeric structure, large vacuole inclusions, and mitochondrial swelling with extensive fractionation of the cristae (Iwasaki and Suzuki, 1991; Papadopoulou et al., 1999; Santos et al., 2002; Zhou et al., 2001b). As was shown previously (Santos et al., 2002), carvedilol restored mitochondrial calcium loading capacity and tissue morphology in DOX-injected animals. The novelty in this investigation is that atenolol, which does not possess antioxidant activity, was without effect against DOX-induced cardiac mitochondrial toxicity and histopathology. Atenolol did not prevent the DOX-induced decrease in mitochondrial calcium loading capacity or calcium-induced mitochondrial swelling, or the cardiac histopathology observed after repeated DOX treatments. The results are strong evidence that it is the antioxidant effect, rather than the $\beta$-adrenoceptor blockage activity, that is responsible for the cardioprotective action of carvedilol.

The interference with mitochondrial calcium homeostasis and mitochondrial swelling caused by DOX has been attributed to induction of the mitochondrial permeability transition, MPT (Solem et al., 1996; Zhou et al., 2001a, 2001b). Induction of the MPT occurs in response to numerous conditions and is suggested to reflect the transformation of a specific pore from a low-conductance to a high-conductance state that is permeable to solutes up to $1500 \mathrm{Da}$ (Bernardi, 1999). Numerous chemicals have been demonstrated to induce this transition, the majority of which are either direct or indirect-acting oxidants. Petronilli et al. (1994) and Chernyak and Bernardi (1996) provide evidence for the regulation of the MPT by the redox state of critical cysteinyl thiols associated with the pore complex. Our results confirm MPT inhibitory activity of carvedilol demonstrated in vitro and ascribed to the potent antioxidant properties of the drug (Oliveira et al., 2001). The significance of the current investigation is the demonstration of protection against the MPT by carvedilol in vivo, which we attribute the cardioprotection afforded by carvedilol to its antioxidant, as opposed to $\beta$-adrenergic antagonist properties.

DOX was also previously shown to decrease cardiac tissue ATP/ADP ratio (Chacon et al., 1992), which was confirmed by the present study (Table 3 ). Interestingly, both carvedilol and atenolol exhibited an energy sparing effect. It may be that by reducing heart rate, non-selective $\beta$-adrenergic receptor antagonists limit cardiac energy expenditure 
and thereby exhibit this energy saving effect (Abiko et al., 1994), which occurs independently of any antioxidant properties. Accordingly, by reducing heart rate, atenolol decreases ATP consumption demands and thereby preserves the high-energy phosphate charge of the cell, although mitochondrial ATP synthesis may be partially compromised by the DOX treatment. Despite the maintenance of the ATP/ ADP ratio by both carvedilol and atenolol, only carvedilol was able to preserve mitochondrial function and myocardial ultrastructure, suggesting that maintenance of normal energy levels does not prevent per se the histopathology caused by DOX. Failure of AT in counteracting DOX cardioselective toxicity is unlikely to be due to deficient dose selection. In fact, as previously described, clinical trials have demonstrated equipotent effects of $\mathrm{CV}$ and $\mathrm{AT}$ regarding reduction of blood pressure in humans (McTavish et al., 1993; Hall et al., 1991).

In conclusion, the present investigation extends earlier reports regarding the protective actions of carvedilol against the DOX-induced cardiotoxicity by demonstrating that this protective effect is due mainly to its antioxidant, and not $\beta$ adrenergic properties. Consequently, efforts to engineer new cardioprotective agents should focus on maximizing the antioxidant and not necessarily the autonomic properties of the drug. The results offer important substantiation for using this pharmacologically active agent as an adjunct to minimize the mitochondrial cardiomyopathy that limits the therapeutic success of DOX antineoplastic therapy.

\section{Acknowledgments}

This work was supported by the NIH grant HL 58016 . Paulo J. Oliveira is supported by a grant from the Portuguese Foundation for Science and Technology (PRAXIS XXI/BD/21494/99). The expert assistance of Jamie Denninger, Jessica Berthiaume, and Tim O'Brien is greatly acknowledged.

\section{References}

Abiko, Y., Gotoh, H., Yokoyama, T., Abiko, T., Hashizume, H., Akiyama, K., 1994. Bopindolol and its metabolite 18-053 attenuate regional myocardial acidosis during partial occlusion of the coronary artery in dogs. Arch. Int. Pharmacodyn. Ther. 327, 40-55.

Bernardi, P., 1999. Mitochondrial transport of cations: channels exchangers and permeability transition. Physiol. Rev. 79, 1127-1155.

Bradford, M.M., 1976. A rapid and sensitive method for the quantitation of microgram quantities of protein utilizing the principle of protein-dye binding. Anal. Biochem. 72, 248-254.

Broekemeier, K.M., Dempsey, M.E., Pfeiffer, D.R., 1989. Cyclosporin a is a potent inhibitor of the inner membrane mitochondrial transition in liver mitochondria. J. Biol. Chem. 264, 7826-7830.

Chacon, E., Ulrich, R., Acosta, D., 1992. A digitized-fluorescence-imaging study of mitochondrial $\mathrm{Ca} 2+$ increase by doxorubicin in cardiac myocytes. Biochem. J. 281, 871-878.

Chernyak, B.V., Bernardi, P., 1996. The mitochondrial permeability tran- sition pore is modulated by oxidative agents through both pyridine nucleotides and glutathione at two separate sites. Eur. J. Biochem. 238, 623-630.

DeAtley, S.M., Aksenov, M.Y., Aksenova, M.V., Harris, B., Hadley, R., Harper, P.C., Carney, J.M., Butterfield, D.A., 1999. Antioxidants protect against reactive oxygen species associated with adriamycin-treated cardiomyocytes. Cancer Lett. 136, 41-46.

Demant, E.J.F., 1991. Inactivation of cytochrome $c$ oxidase activity in mitochondrial membranes during redox cycling of doxorubicin. Biochem. Pharmacol. 41, 543-552.

Doroshow, J.H., 1983. Anthracycline antibiotic-stimulated superoxide, hydrogen peroxide, and hydroxyl radical production by NADH dehydrogenase. Cancer Res. 43, 4543-4551.

Estabrook, R.W., 1967. Mitochondrial respiratory control and the polarographic measurement of ADP:O ratios. Methods Enzymol. 10, 41-47.

Hall, S., Prescott, R.I., Hallman, R.J., Dixon, S., Harvey, R.E., Ball, R.G., 1991. A comparative study of carvedilol, slow release nifedipine, and atenolol in the management of essential hypertension. J. Cardiovasc. Pharmacol. 18 (Suppl. 4), S35-S38.

Hrdina, R., Gersl, V., Klimtová, I., Simunek, T., Machácková, J., Adamcová, M., 2000. Anthracycline-induced cardiomyopathy. Acta Med. 43, $75-82$.

Iwasaki, T., Suzuki, T., 1991. Ultrastructural alterations of the myocardium induced by doxorubicin. Virchows Arch. B Cell Pathol. 60, 35-39.

Jones, D.P., 1981. Determination of pyridine dinucleotides in cell extracts by high-performance liquid chromatography. J. Chromatography 225, 446-449

Kamo, N., Muratsugu, M., Hongoh, R., Kobatake, Y., 1979. Membrane potential of mitochondria measured with an electrode sensitive to tetraphenyl phosphonium and relationship between proton electrochemical potential and phosphorylation potential in steady state. J. Membr. Biol. 49, $105-121$

Kotsinas, A., Gorgoulis, V., Zacharatos, P., Zioris, H., Triposkiadis, F., Donta, I., Kyriakidis, M., Karayannacos, P., Kittas, C., 1999. Antioxidant agent nimesulid and $\beta$-blocker metoprolol do not exert protective effects against rat mitochondrial DNA alterations in adriamycin-induced cardiotoxicity. Biochem. Biophys. Res. Commun. 254, 651-656.

Kowaltowski, A.J., Vercesi, A.E., 1999. Mitochondrial damage induced by conditions of oxidative stress. Free Radical Biol. Med. 26, 463-471.

Lee, V., Randhawa, A., Singal, P.K., 1991. Adriamycin-induced myocardial dysfunction in vitro is mediated by free radicals. Am. J. Physiol. 261, H989-H995.

Levine, R.L., Garland, D., Oliver, C.N., Amici, A., Climent, I., Lenz, A.-G., Ahn, B.-W., Shaltiel, S., Stadtman, E.R., 1990. Determination of carbonyl content in oxidatively modified proteins. Methods Enzymol. 186, $464-478$

Matsui, H., Morishima, I., Numaguchi, Y., Toki, Y., Okumura, K., Hayakawa, T., 1999. Protective effects of carvedilol against doxorubicininduced cardiomyopathy in rats. Life Sci. 65, 1265-1274.

McTavish, D., Campoli-Richards, D., Sorkin, E.M., 1993. Carvedilol, a review of its pharmacodynamic and pharmacokinetic properties, and therapeutic efficacy. Drugs 45 (2), 232-258.

Mimnaugh, E.G., Trush, M.A., Bhatnagar, M., Gram, T.E., 1985. Enhancement of reactive oxygen-dependent mitochondrial membrane lipid peroxidation by the anticancer drug adriamycin. Biochem. Pharmacol. 34, $847-856$

Monti, E., Cova, D., Guido, E., Morelli, R., Oliva, C., 1996. Protective effect of the nitroxide tempol against the cardiotoxicity of adriamycin. Free Radical Biol. Med. 21, 463-470.

Noguchi, N., Nishino, K., Niki, E., 2000. Antioxidant action of the antihypertensive drug, carvedilol, against lipid peroxidation. Biochem. Pharmacol. 59, 1069-1076.

Oliveira, P.J., Santos, D.L., Moreno, A.J.M., 2000. Carvedilol inhibits the exogenous NADH dehydrogenase in rat heart mitochondria. Arch. Biochem. Biophys. 374, 279-285.

Oliveira, P.J., Coxito, P.M., Rolo, A.P., Santos, D.L., Palmeira, C.M., Moreno, A.J.M., 2001. Inhibitory effect of carvedilol in the high-conduc- 
tance state of the mitochondrial permeability transition pore. Eur. J. Pharmacol. 412, 231-237.

Olson, R.D., Mushlin, P.S., 1990. Doxorubicin cardiotoxicity: analysis of prevailing hypotheses. FASEB J. 4, 3076-3086.

Palmeira, C.M., Serrano, J., Kuehl, D.W., Wallace, K.B., 1997. Preferential oxidation of cardiac mitochondrial DNA following acute intoxication with doxorubicin. Biochim. Biophys. Acta 1321, 101-106.

Papadopoulou, L.C., Theophilidis, G., Thomopoulos, G.N., Tsiftsoglou, A.S., 1999. Structural and functional impairment of mitochondria in adriamycin-induced cardiomyopathy in mice: suppression of cytochrome $c$ oxidase II gene expression. Biochem. Pharmacol. 57, $481-489$

Petronilli, V., Constantini, P., Scorrano, L., Colonna, R., Passamonti, S., Bernardi, P., 1994. The voltage sensor of the mitochondrial permeability transition pore is tuned by the oxidation-reduction state of vicinal thiols. J. Biol. Chem. 269, 16638-16642.

Prohaska, J.R., 1983. Changes in tissue growth, concentrations of copper, iron, cytochrome oxidase and superoxide dismutase subsequent to dietary or genetic copper deficiency in mice. J. Nutr. 113, 2048-2058.

Rajdev, S., Reynolds, I.J., 1993. Calcium Green-5N, a novel fluorescent probe for monitoring high intracellular free $\mathrm{Ca}^{2+}$ concentrations associated with glutamate excitotoxicity in cultured rat brain neurons. Neurosci. Lett. 162, 149-152.

Santos, D.L., Moreno, A.J.M., Leino, R.L., Froberg, M.K., Wallace, K.B., 2002. Carvedilol protects against doxorubicin-induced mitochondrial cardiomyopathy. Toxicol. Appl. Pharmacol. 185, 218-227.

Sokolove, P.M., Shinaberry, R.G., 1988. $\mathrm{Na}^{+}$-independent release of $\mathrm{Ca}^{2+}$ from rat heart mitochondria-induction by adriamycin aglycone. Biochem. Pharmacol. 37, 803-812.

Solem, L.E., Henry, T.R., Wallace, K.B., 1994. Disruption of mitochondrial calcium homeostasis in vivo following chronic doxorubicin administration. Toxicol. Appl. Pharmacol. 129, 214-222.

Solem, L.E., Heller, L.J., Wallace, K.B., 1996. Dose-dependent increase in sensitivity to calcium-induced mitochondrial dysfunction and cardiomyocyte cell injury by doxorubicin. J. Mol. Cell. Cardiol. 28, $1023-1032$.

Van Vleet, J.F., Ferrans, V.J., Weirich, W.E., 1980. Cardiac disease induced by chronic adriamycin administration in dogs and evaluation of vitamin E and selenium as cardioprotectants. Am. J. Pathol. 99, 13-42.

Xu, M.F., Tang, P.L., Qian, Z.M., Ashraf, M., 2001. Effects by doxorubicin on the myocardium are mediated by oxygen free radicals. Life Sci. 68 , $889-901$.

Yin, X., Wu, H., Chen, Y., Kang, Y.J., 1998. Induction of antioxidants by adriamycin in mouse heart. Biochem. Pharmacol. 56, 87-93.

Yue, T.-L., McKenna, P.J., Ruffolo Jr., R.R., Feuerstein, G., 1992. Carvedilol, a new $\beta$-adrenoceptor antagonist and vasodilator antihypertensive drug, inhibits superoxide release from human neutrophils. Eur. J. Pharmacol. 214, 277-280.

Zhou, S., Heller, L.J., Wallace, K.B., 2001a. Interference with calciumdependent mitochondrial bioenergetics in cardiac myocytes isolated from doxorubicin-treated rats. Toxicol. Appl. Pharmacol. 175, 60-67.

Zhou, S., Starkov, A., Froberg, M.K., Leino, R.L., Wallace, K.B., 2001b. Cumulative and irreversible cardiac mitochondrial dysfunction induced by doxorubicin. Cancer Res. 61, 771-777. 